\title{
Phytochemicals modulate carcinogenic signaling pathways in breast and hormone-related cancers
}

This article was published in the following Dove Press journal:

OncoTargets and Therapy

6 August 2015

Number of times this article has been viewed

\section{Roxana Cojocneanu \\ Petric, ${ }^{1,2}$ Cornelia \\ Braicu, ${ }^{2}$ Lajos Raduly, ${ }^{2,3}$ \\ Oana Zanoaga, ${ }^{2}$ Nicolae \\ Dragos, ${ }^{1,4}$ Paloma Monroig, ${ }^{5}$ \\ Dan Dumitrascu, ${ }^{6}$ loana \\ Berindan-Neagoe ${ }^{2,5,7,8}$}

'Department of Biology, Babes-Bolyai

University, ${ }^{2}$ Research Center for

Functional Genomics, Biomedicine and Translational Medicine, Iuliu Hatieganu University of Medicine and Pharmacy, ${ }^{3}$ Department of Physiopathology, Faculty of Veterinary Medicine, University of Agricultural Science and Veterinary Medicine, ${ }^{4}$ Department of Taxonomy and Ecology, Institute of Biological Research, Cluj-Napoca, Romania; ${ }^{5}$ Department of Experimental Therapeutics, MD Anderson Cancer Center, Houston, TX, USA; ${ }^{6} 2$ nd Department of Internal Medicine, luliu Hatieganu University of Medicine and Pharmacy, ${ }^{7}$ Department of Functional Genomics and Experimental Pathology, The Oncology Institute "Prof Dr Ion Chiricuță", ${ }^{8}$ Department of Immunology, luliu Hatieganu University of Medicine and Pharmacy, Cluj-Napoca, Romania

Correspondence: Roxana Cojocneanu Petric; Cornelia Braicu

Research Center for Functional

Genomics, Biomedicine and Translational Medicine, luliu Hatieganu University of Medicine and Pharmacy, 23 Marinescu Street, 4th floor, Cluj-Napoca 400337, Romania

Tel +40 74535 3205; +40 754303833

Email cojocneanur@gmail.com
Abstract: Over the years, nutrition and environmental factors have been demonstrated to influence human health, specifically cancer. Owing to the fact that cancer is a leading cause of death worldwide, efforts are being made to elucidate molecular mechanisms that trigger or delay carcinogenesis. Phytochemicals, in particular, have been shown to modulate oncogenic processes through their antioxidant and anti-inflammatory activities and their ability to mimic the chemical structure and activity of hormones. These compounds can act not only by influencing oncogenic proteins, but also by modulating noncoding RNAs such as microRNAs and long noncoding RNAs. Although we are only beginning to understand the complete effects of many natural compounds, such as phytochemicals, researchers are motivated to combine these agents with traditional, chemo-based, or hormone-based therapies to fight against cancer. Since ongoing studies continue to prove effective, herein we exalt the importance of improving dietary choices as a chemo-preventive strategy.

Keywords: natural compounds, dietary polyphenols, epigallocatechin gallate, curcumin, genistein, noncoding RNA, cancer

\section{Introduction}

Almost two centuries ago, the French lawyer/politician and gastronome Anthelme Brillat-Savarin stated "you are what you eat". ${ }^{1}$ Since then, nutrition awareness has become very popular, and over the past years we have witnessed an increase in the number of people who devote time to educate and inform themselves about their selection of food products for consumption. Numerous scientific studies have shown that our eating habits can directly affect weight gain or loss, blood cholesterol levels, blood sugar levels, etc. However, the food we consume has an additional potential to act at a smaller scale, namely at molecular level, thus supporting the fact that foods are nutraceuticals.

Food products are advertised as agents having nutritional value as well as an effect on biologic functions, and they achieve their dynamic properties due to the presence of natural compounds named phytochemicals. These substances can be classified into various categories according to their structure or function (Figure 1, Table 1), but they usually act by mimicking the hormones. Good examples of this are phytoestrogens. In addition, phytochemicals can act by exerting antioxidant and anti-inflammatory effects. Nevertheless, the fact that phytochemicals have the potential of improving the lives of patients who suffer from various malignant diseases, such as cancer, is extremely interesting and exciting. Thus, the purpose of this manuscript is to evaluate de impact of the phytochemicals epigallocatechin gallate (EGCG), curcumin, and genistein on hormone-related cancers, especially breast cancer.

Nowadays, despite the exponential increase in oncological studies, the incidence of cancer continues to increase at an alarming pace. According to the latest GLOBOCAN 


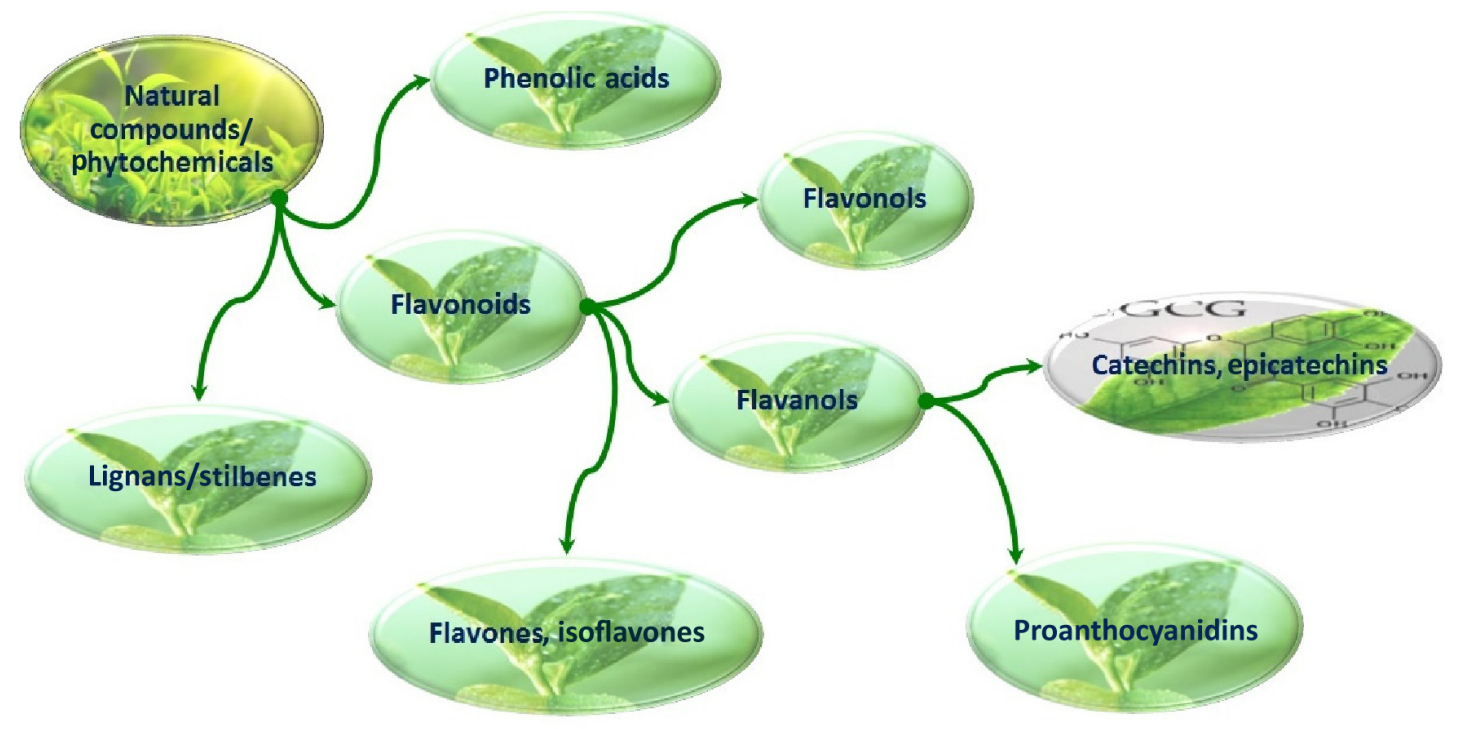

Figure I Classification of the principal types of phytochemicals.

statistics, during the year 2012 over 8 million people died of cancer, 32.6 million patients were diagnosed with this malignant disease during the previous 5 years, and a little over 14 million new oncological patients were identified. ${ }^{2}$ These facts are alarming, and most certainly reinforce the importance of making efforts as a scientific community, to elucidate the molecular mechanisms that trigger carcinogenesis, with purpose of improving the lives of cancer patients.
Among the different types of cancer, breast cancer causes the highest number of deaths among women worldwide. ${ }^{2}$ Breast cancer is a highly heterogeneous tumor that is subclassified into several subtypes based on their molecular characteristics. Among the several existing subclassifications of breast cancer, a subtype that generates great concern among caregivers is the one whose cells do not present estrogen receptors (ERs) on their surface, namely, ER-negative

Table I Classification of phytochemicals

\begin{tabular}{|c|c|c|c|c|}
\hline \multicolumn{4}{|c|}{ Classification of phytochemicals, examples } & \multirow{2}{*}{$\begin{array}{l}\text { Sources } \\
\text { Chestnuts (boiled or roasted), witch } \\
\text { hazel, tea leaves, oak bark, rhubarb, etc }\end{array}$} \\
\hline \multirow[t]{11}{*}{ Phenolics } & \multirow[t]{2}{*}{ Phenolic acids } & Hydroxybenzoic acids & $\begin{array}{l}\text { Gallic, vanillic, } \\
\text { syringic }\end{array}$ & \\
\hline & & Hydroxycinnamic acids & $\begin{array}{l}\text { p-Coumaric, caffeic, } \\
\text { ferulic, sinapic }\end{array}$ & $\begin{array}{l}\text { Barley, eucalyptus, coffee, } \\
\text { Arabidopsis, Hibiscus, etc }\end{array}$ \\
\hline & \multirow[t]{6}{*}{ Flavonoids } & Flavonols & $\begin{array}{l}\text { Quercetin, kaempferol, } \\
\text { myricetin }\end{array}$ & $\begin{array}{l}\text { Aloe vera, European elderberry, soy, } \\
\text { St John's wort, tomatoes, red onions, etc }\end{array}$ \\
\hline & & Flavones & Apigenin, luteolin & $\begin{array}{l}\text { Celery, parsley, chamomile tea, } \\
\text { green peppers, thyme, oregano, etc }\end{array}$ \\
\hline & & Flavanols (catechins) & $\begin{array}{l}\text { Catechin, epicatechin, } \\
\text { epigallocatechin gallate }\end{array}$ & $\begin{array}{l}\text { White tea, green tea, persimmon, } \\
\text { pomegranate, cocoa beans, etc }\end{array}$ \\
\hline & & Flavanones & Eriodictyol, hesperetin & Citrus fruits, rose hip, mountain balm, etc \\
\hline & & Anthocyanidins & $\begin{array}{l}\text { Cyanidin, pelargonidin, } \\
\text { malvidin }\end{array}$ & $\begin{array}{l}\text { Grapes, berries, red cabbage, red } \\
\text { onions, plums, kidney beans, geranium, etc }\end{array}$ \\
\hline & & Isoflavonoids & Genistein, glycitein & Lupin, fava beans, soy, coffee, etc \\
\hline & \multicolumn{3}{|l|}{ Stilbenes } & Grapes, etc \\
\hline & \multicolumn{3}{|l|}{ Coumarins } & Tonka bean, vanilla grass, etc \\
\hline & \multicolumn{3}{|l|}{ Tannins } & Eucalyptus, geranium, etc \\
\hline Carotenoids & \multicolumn{3}{|c|}{$\begin{array}{l}\alpha \text {-carotene, } \beta \text {-carotene, } \\
\text { lutein, zeaxanthin, lycopene }\end{array}$} & Carrots, broccoli, spinach, zucchini, etc \\
\hline \multicolumn{4}{|l|}{ Alkaloids } & Poppy, tomatoes, potatoes, etc \\
\hline $\begin{array}{l}\text { Organosulfur } \\
\text { compounds }\end{array}$ & \multicolumn{3}{|c|}{$\begin{array}{l}\text { Isothiocyanates, indoles, } \\
\text { allyl sulfur compounds }\end{array}$} & $\begin{array}{l}\text { Cabbage, broccoli, spinach, garlic, } \\
\text { onions, etc }\end{array}$ \\
\hline
\end{tabular}


tumors. These tumors behave in an aggressive manner, and are resistant/unsusceptible to the effect of hormone therapies, particularly ER modulators.

\section{Genome modulatory role of natural compounds}

Both nutritional agents and environmental factors have a direct impact on the epigenetic machinery in human cells. Regarding dietary natural compounds and polyphenols, studies have shown that they are involved in modulating the epigenetic mechanisms and in shaping the epigenome by participating in three crucial processes: DNA methylation, histone modifications, and post-transcriptional regulation of genes via noncoding RNAs (ncRNAs), especially miRNAs. ${ }^{3}$ As a result of any of these dynamic changes, the fate of each gene is decided in regard to whether it will be translated into a protein or not. The involvement of phytochemicals with regulative behavior such as these could modify the activity of proteins as well as ncRNAs, and for this reason they have been said to have a promising role in pharmacogenomics.

Recent studies are aimed at identifying new, more efficiently targeted anticancer drugs, but more so, they are focused at trying to find innovative means to potentiate and improve existing therapies. This could most likely be achieved by deciphering molecular mechanisms that are or can be made vulnerable to specific therapeutic agents. ${ }^{4}$ For this purpose, phytochemicals have been extensively tested, alone or in combination with common drugs, to observe their modulation capabilities to obtain an additive or synergic therapeutic effect. "Phytochemicals" is a generic term for various compounds naturally occurring in plants, which are mainly responsible for their taste, smell, or color. They have been shown to exhibit different beneficial effects on human health. Most phytochemicals (such as flavonoid compounds) exert their functional roles through their antioxidant, chemopreventive, and anti-inflammatory capabilities, ${ }^{5}$ for example, EGCG is a very important polyphenol compound extracted from green tea. EGCG is mainly known for its role as a cancer modulator because of its antioxidant, proapoptotic, and antiangiogenic effects. ${ }^{6-11}$ It has been extensively studied due to its reduced costs and decreased cellular toxicity. Additionally, it is relatively easy to find in many common foods such as tea, chocolate, grapes, grape seeds, etc. ${ }^{12,13}$

Alongside the beneficial effects of natural compounds such as EGCG, it is important to consider the fact that these agents could still display cytotoxic effects, which can be sometimes due to inappropriately high doses, unsuitable combinations, or improper use. Indeed, it is like the saying of the Renaissance scientist Paracelsus (presumed parent of toxicology), "dosis facit venenum - the dose makes the poison". ${ }^{14}$ Some examples of toxicities caused by phytochemicals include the goitrogenic properties of some components of the Brassica plants, the hemolytic effects of fava beans on certain genetically susceptible populations, and the agglutination caused by lectins. ${ }^{15}$ Nonetheless, if tested thoroughly, phytochemicals can improve the life of patients suffering from various diseases such as cancer, particularly when administered in combination with conventional therapies.

Breast cancers represent a very heterogeneous group of tumors to target, and the application of phytochemicals to treat patients with breast cancer would represent an attractive approach to complement conventional therapies. Regarding the ER-positive tumor type, studies have shown that estrogen generally supports malignant progression by favoring the cancer phenotype, especially in hormone-dependent cancers such as mammary tumors, via mechanisms that alter the routine transcription of estrogen-responsive genes. This occurs when ER dimers, belonging to the nuclear receptor superfamily of ligand-activated transcription factors, bind to the estrogen response elements located on the promoters of the genes that they regulate. Nuclear ERs are not the only structures that are involved in the process of supporting tumor development in breast cancer. Another active player is ER alpha $(\mathrm{ER} \alpha)$ located in the cytosol and at mitochondrial level can also contribute to various nongenomic signaling pathways. For instance, mitochondrial ER $\alpha$ signaling takes an active role in the inhibition of intrinsic apoptotic pathways. ${ }^{16,17}$

For ER-positive tumors, one of the most used conventional therapies is selective estrogen receptor modulator (SERM) such as tamoxifen. This drug acts by specifically binding to ERs on the surface of cancer cells, thereby blocking the hormone-induced signaling pathways that sustain tumor proliferation. ${ }^{18-20}$ While this agent works efficiently and represents a therapeutic alternative for estrogen-positive tumors, the drug is not useful for tumor subtypes that are not driven by ERs. In this sense, phytochemicals such as EGCG, or other natural compounds, could work by modulating the genetic expression of tumors that are not hormone driven, and alter their sensitivity to antihormonal therapies such as SERMs. The molecular mechanisms by which these phytochemicals manifest their effect upon hormone-induced signaling pathways of malignant cells are not completely understood. However, studies have linked their mechanism of action to the expression and function of certain genes or ncRNAs. Similarly, in ER-negative cancers, polyphenols 
have been known to regain the ER phenotype, ${ }^{21}$ thereby making tumor cells sensible to the antiestrogenic effects of tamoxifen, and possibly to other anticancer drugs.

Several groups of scientists, including Li et al have worked on the idea of reinstating the sensitivity of tumors that possess a characteristic ER-negative phenotype.$^{21}$ According to them, if reverted, these tumors could regain sensitivity to known chemotherapeutic treatments. Some of their work branches out of the hypothesis that the lack of $E R$ gene expression in cancer subtypes, such as triple negative, is not caused exclusively by mutations. More so, it can be the result of other alterations such as epigenetics that modulate what can be referred to as the "hormone resistance machinery", or genes and proteins that influence hormones. Some mechanisms that have shown to validate the hypothesis of these groups are epigenetic means of gene silencing, which seem to play an important role, ${ }^{21,22}$ especially hypermethylation at the DNA level in the ER gene promoter. ${ }^{23}$ Additionally, several types of histone modifications, ${ }^{24,25}$ such as acetylations and deacetylations, have been shown to influence reading and interpretation of the genetic code, and this can affect hormone-induced cell signaling pathways. ${ }^{23,26}$

Since ER-negative tumors behave differently from their receptor-positive counterparts, not only by being more heterogeneous but also by displaying a greater and more aggressive metastatic capacity, more efforts need to be made to re-sensitize these cells to the effects of endocrine therapeutic options, such as SERMs. An option to address this would be to use histone deacetylase inhibitors (HDAC inhibitors), which have proved their clinical significance in acting against several types of cancer. ER tumors have also shown to increase their sensitivity to known therapies when treated with drugs such as demethylating agents, which are involved in silencing gene expression. An example of a demethylating agent is DNMT, a DNA methyltransferase, which has an effect against the hypermethylation of the promoter of ER, leading to a decrease in its mRNA and thereby a depleted protein expression. ${ }^{27}$

Among the studies of natural compounds focused on discovering and characterizing the molecular mechanisms that underlie the onset, advancement, and development of cancer, many concentrated on discovering new means and novel compounds that can be used to modulate, and eventually control, subcellular events that lead to carcinogenesis. Prevention of cancer through dietary intervention has received an increasing interest, and dietary polyphenols, for example, have become not only important potential chemopreventive but also therapeutic natural agents that have the capability to interfere with oncogenic signaling pathways..$^{28}$ Nowadays, studies also have a more ambitious aim such as finding and developing targeted drugs that can act at the core of molecular events that trigger or modulate particular steps in the stepwise progress of tumor development and disease progression (Figure 2). In order to achieve this, it is necessary to also address another aspect, namely, the poor bioavailability of phytochemicals, because of which most phytochemical compounds reach the targeted sites at subtherapeutic concentrations..$^{29,30}$ In the case of curcumin,

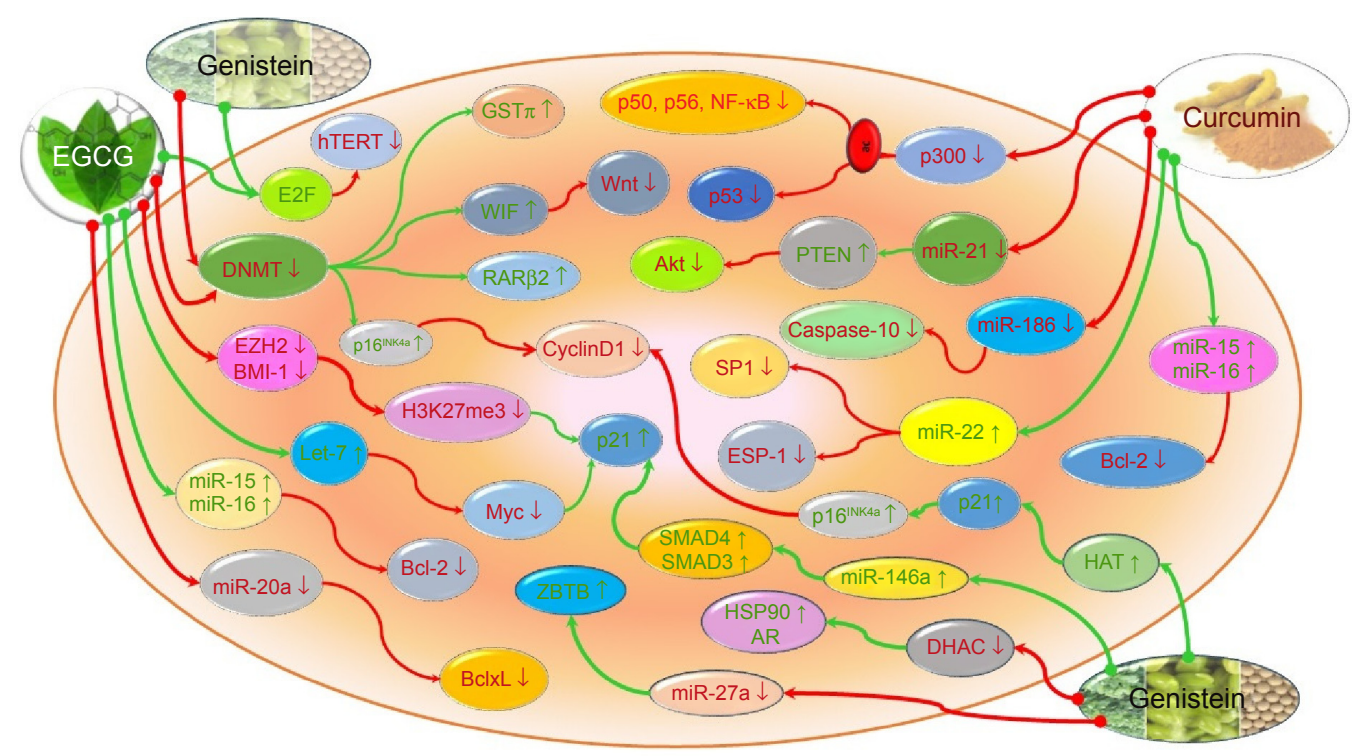

Figure 2 Modulatory effects of EGCG, curcumin, and genistein. Abbreviation: EGCG, epigallocatechin gallate. 
for instance, this limitation has been amended through the synthesis of functionally identical analogs with improved efficiency ${ }^{29,31}$ and by constantly testing novel delivery systems, including liposomes, micelles, and various functionalized nanoparticles. ${ }^{32-34}$ Although these drug carriers still need to undergo further in vivo assessments, the promising results support the potential of phytochemicals to be used as chemopreventive and chemotherapeutic agents in the clinic.

\section{Epigallocatechin gallate}

Epigallocatechin gallate (EGCG) (PubChem chemical structure identifier CID: 65064, Figure 3) is a polyphenol present in several natural sources, but mainly in green tea, which is among the most common beverages worldwide. ${ }^{35}$ EGCG has been long studied, and is known to have beneficial effects in various pathologies including neurodegenerative diseases, diabetes, strokes, and obesity. It can also have chemopreventive effects in several types of cancers. ${ }^{36}$ Its antioxidant effect appears to counteract the inflammatory processes that precede the development of malignancy, such as cellular transformation, sustained proliferation, and other characteristics that lead to tumorigenesis.

One of the ways that EGCG manifests its protective/ preventive effect against cancer has been proven in vitro in both cervical and breast cancer cells. It does so by is by detaining the cell cycle in the G1 phase $\mathrm{e}^{37,38}$ and by influencing the synthesis of several proteins, such as CDK1 and cyclins $\mathrm{D}$ and $\mathrm{E}$ (which tightly regulate cell cycle progression). In addition, this particular polyphenol can induce processes such as apoptosis, positively regulating the function of proteins

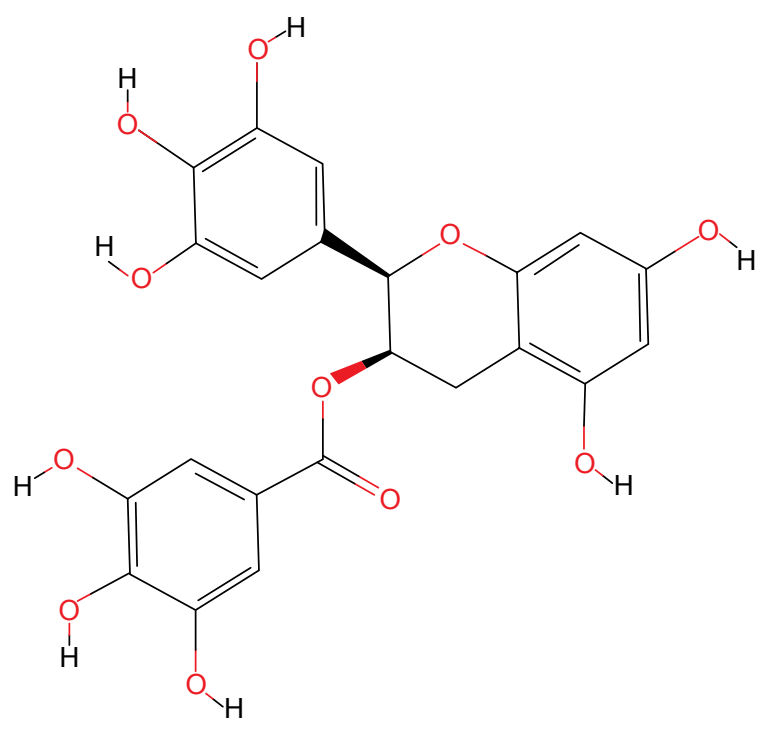

Figure 3 The chemical structure of EGCG. Abbreviation: EGCG, epigallocatechin gallate. such as pRb, p53, p27, etc, especially in breast, prostate, and bladder cancer cells in vitro. ${ }^{38-40}$

One interesting aspect observed in different studies is that malignant cells seem to be more susceptible to the antitumor effect of bioactive polyphenols, when compared with normal, untransformed cells. ${ }^{41,42}$ The ability of phytochemicals to act on cancer cells in a selective manner has great importance in what concerns the concept of targeted therapy. Most conventional chemotherapy is nonspecific for cancer cells and also affects nonmalignant tissues; thus, it has unpleasant and potentially dangerous side effects. ${ }^{43}$ On the other hand, the lack of toxicity on normal cells displayed by many phytochemicals, together with their ability to act in a synergistic manner with many anticancer drugs, ${ }^{44-46}$ makes phytochemicals interesting and appealing from the therapeutic point of view. Moreover, dietary polyphenols, including EGCG, administered in low doses appear to promote survival genes and protective mechanisms by activating the mitogen-activated protein kinase (MAPK) signaling pathway; however, in higher doses they can induce antitumorigenic processes such as apoptosis. ${ }^{47}$ EGCG can influence programmed cell death by triggering and activating proapoptotic proteins, such as caspases 3, 8, and 9, and by downregulating the natural inhibitors of these cellular process, such as Bcl2, Bid, XIAP, or IAP2. ${ }^{48,49}$ This effect is enhanced alongside by dietary polyphenols upregulating p53, p21, and Bax, as shown in a study conducted by Hastak et al using the RNA interference technique of siRNA-p53 inactivation. ${ }^{39}$ Additionally, we confirmed in our laboratory the role of EGCG as an activator of apoptosis through thorough studies, some of which showed a synergistic effect on combining the treatment of HeLa cells with EGCG and siRNA-p53, which reversed the oncogenic role of the mutated p53 gene present in cancer cells. This therapeutic effect was achieved by modulating various genes that belong to families such as caspases, TNF receptor associated factor, Caspase recruitment domain, death domain, or $\mathrm{Bcl} 2$. Thus, this suggests that EGCG has a role as gene expression co-activator, and therefore could be used as an anticancer therapy. ${ }^{50}$ Similar results were obtained when treating cervical cancer cells only with EGCG, then performing gene expression analysis using polymerase chain reaction (PCR) array technology. The treatment also contributed to the activation of caspasemediated apoptosis, via BAK1 upregulation. ${ }^{51}$

Previous studies suggest that the hyperactivation of MAPK signaling pathway may constitute one of the mechanisms that lead to the loss of ER $\alpha$ expression in breast cancer, promoting an ER-negative phenotype. ${ }^{16}$ Nonetheless, this 
process is reversible when the MAPK signaling pathway is inhibited, emphasizing the necessity of further studies to elucidate these molecular mechanisms.

Nuclear factor- $\mathrm{\kappa B}(\mathrm{NF}-\mathrm{\kappa B})$ is another signaling pathway that is usually deregulated in cancer. In ER-negative breast cancer cell models, NF- $\mathrm{\kappa B}$ is constitutively active. Nonetheless, it barely shows any type of activity in ER-positive/ Her2-negative cell lines. Zhou et al have confirmed this exact prediction by showing that high NF- $\mathrm{KB}$ activity positively correlates with a decreased $\mathrm{ER} \alpha$ expression, as obtained in a study conducted on 81 patients. ${ }^{52}$ In this manner, it promotes cell survival mechanisms, while at the same time inhibits apoptosis-mediated cell death. ${ }^{53}$ Because of this, the role of the dietary polyphenolic compound EGCG has been studied and considered as an approach to help balance the signaling pathway toward the desired direction.

Regarding the effect of certain natural compounds on oncogenic signaling pathways, EGCG was observed to decrease the production of NF- $\kappa \mathrm{B}$. This diminished the effect that NF- $\kappa \mathrm{B}$ had on the expression levels of ER $\alpha .{ }^{48,54}$ Thus, it may be stated that this phytochemical not only appears to promote the reactivation of the ER expression, but it may be working as a preventive mechanism to lessen the activity of genes that could lead to regaining an ERpositive phenotype. EGCG may be predicted to be achieving this by modulating the levels of significant molecules in key signaling pathways. Alternatively, it is possible that polyphenols, such as EGCG, do not actually revert the hormonal phenotype from ER negative back to ER positive, but just detain a sequence of events responsible for the loss of ER expression. The inhibitory effect that EGCG has on the NF- $\mathrm{KB}$ molecule, and consequently on the signaling pathways it takes part in, appears to achieve a desired effect in breast cancer cells. Regarding patient benefits, this could potentially translate into new therapeutic alternatives for breast cancer tumors. ${ }^{55,56}$

\section{Curcumin}

Curcumin (1,7-bis[4-hydroxy-3-methoxyphenyl]-1E, 6E-heptadiene-3,5-dione) (PubChem chemical structure identifier CID: 969516, Figure 4) is a polyphenolic compound derived from turmeric, an aromatic perennial herbaceous plant from the ginger family named Curcuma longa.$^{35}$ This bright yellow powder, also known as "Indian saffron", is a principal ingredient in curry, and it has also been long used in traditional Asian medicine due to its anti-inflammatory, antimicrobial, and antioxidant properties. ${ }^{57,58}$ Even though curcumin has a reduced bioavailability and is poorly absorbed/rapidly processed, it has promising modulatory

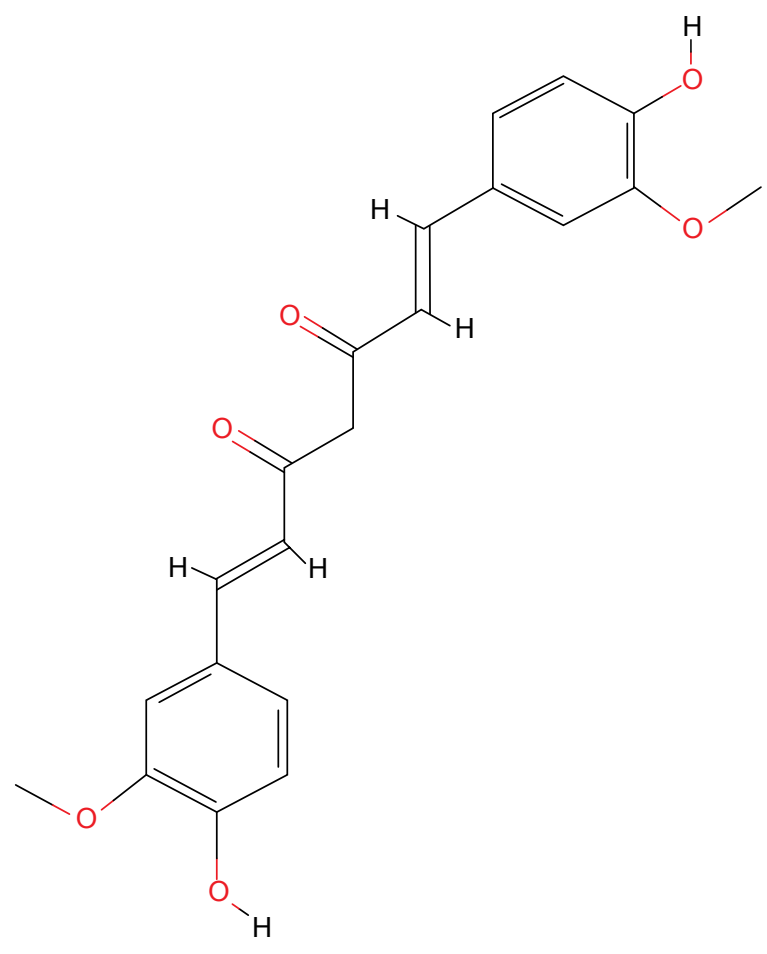

Figure 4 The chemical structure of curcumin.

effects that have led researches to put effort into either enhancing its bioavailability or developing synthetic analogs to further study its antitumorigenic effect.

As mentioned, curcumin is a known anti-inflammatory compound used in traditional Asian medicine. Besides from inhibiting COX2, a known key player in the inflammatory

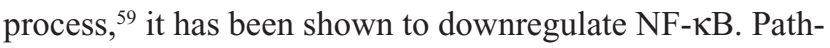
ways activated by NF- $\mathrm{\kappa B}$ are triggered by inflammation, as shown by cellular studies in vitro and on peripheral blood samples from oncogenic patients. ${ }^{60}$ The inhibitory effect that curcumin has on NF- $\mathrm{kB}$ resembles the effect that EGCG has on it. In this manner, it may also interfere with processes that lead to diminished ER expression.

The influential effect of curcumin on NF- $\kappa \mathrm{B}$ also extends to other molecules that are part of its signaling pathway, such as COX2, MMP9, BlcxL, Bcl2 ${ }^{61}$ Further studies have shown that curcumin may also have inhibitory effects on other oncogenic signaling pathways, such as Akt. As a result, it can initiate apoptotic processes and inhibit tumor cell proliferations. ${ }^{62,63}$ Thus, curcumin could potentiate the effect of antihormonal therapy in cancer by positively influencing processes that can reinstate ER expression. Furthermore, it has overall beneficial effects for cancer patients by promoting apoptosis in tumor cells. Nonetheless, further studies still need to be conducted in order to better understand the effects of this dietary polyphenol on breast cancer and how it can be combined with the known therapies. 


\section{Genistein}

Another important dietary natural compound is genistein or 4',5,7-trihydroxyisoflavone (PubChem chemical structure identifier CID: 5280961, Figure 5). ${ }^{35}$ It is an isoflavone found in large quantities in soybeans and, consequently, in most products that contain soy protein. Its structure resembles very much that of estradiol; thus, genistein functions as a phytoestrogen, binding to the ERs, causing its effects in a dose-dependent manner. At low doses $(<1 \mu \mathrm{M})$, genistein acts as an estrogen agonist, promoting cell proliferation. On the other hand, when administered in concentrations higher than $5 \mu \mathrm{M}$, it displays an antagonistic activity by inhibiting the growth of ER-dependent tumor cells. ${ }^{64}$ This fact has been confirmed in recent studies. For example, Lavigne et al worked on a human mammary tumor cell line, MCF-7, and observed that genistein, at low physiological concentrations, sustains the mitogenic activity of cells. However, when administered at pharmacological doses, it promotes programmed cell death, decreasing proliferation. ${ }^{65}$

Genistein is a downregulator of several molecules and signaling pathways known for their involvement in tumorigenesis, cancer development, and progression. For example, it can inhibit protein tyrosine kinases and induce proapoptotic effects in this way. ${ }^{66,67}$ Additionally, isoflavones found in soybeans have antioxidant potential which inhibits the activation of the NF- $\kappa \mathrm{B}$ and the signaling pathways that it takes part in. In both breast and prostate cancers, genistein inhibits tumor cell growth and proliferation in vitro. ${ }^{68,69}$ Interestingly, both of these are cancer types influenced by hormones. ${ }^{70}$ In vivo, the effects produced by both breast and prostate cancers appear to be similar, as displayed by experiments conducted by Davis et al. ${ }^{71}$ By studying the lymphocytes harvested from the blood of volunteers that were administered soy supplements, they observed a protective effect of this leguminous plant against the tumor necrosis factor alpha (TNF $\alpha)$-induced $\mathrm{NF}-\kappa \mathrm{B}$ upregulation.

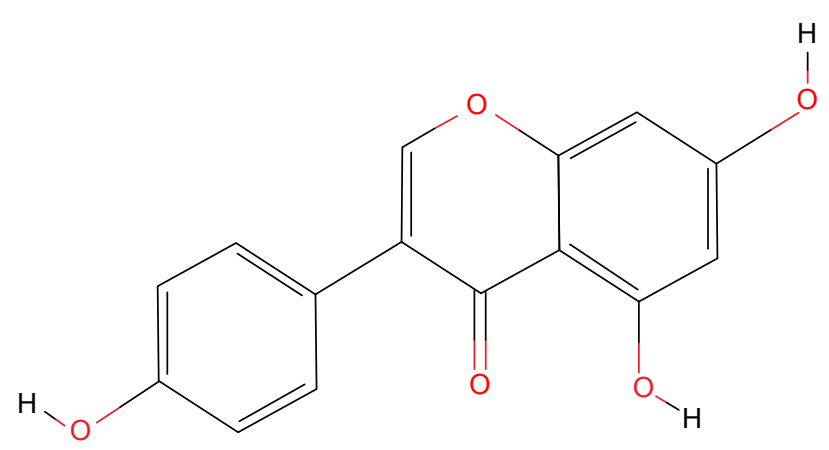

Figure $\mathbf{5}$ The chemical structure of genistein.
Finally, an additional target inhibited by the isoflavone genistein is the Akt kinase. Genistein can downregulate its activity by preventing its phosphorylation. This fact was observed in several studies conducted on hormone-related cancer cell lines. ${ }^{69,72,73}$

According to Kikuno et al genistein inhibits both Akt and NF- $\mathrm{\kappa B}$ in prostate cells by reducing multiple epigenetic mechanisms. ${ }^{74}$ In addition, it could contribute to the prevention of prostate cancer onset by modulating an antiestrogenic effect mediated through heat shock proteins HSP90 and HDAC6. ${ }^{75}$ Other signaling pathways that promote tumorigenesis, such as Wnt/ $\beta$-catenin and Notch signaling, are also inhibited by genistein, and all these data represent promising indications that this natural compound may also be used in combination with traditional, conventional chemotherapy or with hormone therapy to regain/potentiate their effect. ${ }^{76,77}$

\section{The Asian paradox}

A remarkable observation has been noted when comparing breast cancer incidences in Asian women to those in Caucasian and Asian-American women. ${ }^{78}$ Principally, it was observed that when Asian-American women continued to consume a typical Asian diet, with high quantities of soy, fish, rice, tea, and greens, their risk of developing breast cancer was lower than that of Western and Caucasians, in general. On the other hand, when Asian-Americans switched to the Western diet, their breast cancer risk increased just as that of women of the Caucasian descent. ${ }^{70}$

Genistein in particular and soy, in general, have been extensively studied, specifically in regard to their relation with breast cancer. In Asian countries, soy is a staple food, and it is consumed by virtually everybody throughout their lives. Asian women are exposed to soy isoflavones from the very beginning of their existence, and this might be a possible explanation of the risk differences observed between them and Caucasians. Therefore, the increased intake of soy and soy-derived products in childhood and early adolescence seems to confer a degree of protection against the development of breast cancer. ${ }^{79-83}$ Regarding Asian-American women, a possible explanation for them having a higher risk than Asian women might be that the soy-based foods that are produced in the Western countries vary considerably from the traditional Asian ones due to the higher degree of processing. This most likely alters the bioavailability and accessibility of soy isoflavones. ${ }^{84,85}$ These interesting facts raise questions regarding the preventive potential that genistein can have on breast cancer risk. Thus, more studies need to be conducted on this topic in order to elucidate the mechanisms that appear to improve the lives and overall survival of cancer patients. 


\section{ncRNAs, cancer, and natural compounds}

Since the central dogma of molecular biology has recently shifted from the clear, straightforward model of "DNAmRNA-proteins" to the complex labyrinth of ncRNAs, it is not surprising that the effects of natural compounds have also begun to raise interest in the context of miRNA modulation. ncRNAs, and miRNAs in particular, are not only potential biomarkers for the diagnosis and prognosis of cancer, but, as studies have shown, can also be the targets for therapeutic agents, as one miRNA can participate in the modulation of many different molecular pathways involved in malignant initiation, development, and progression.

ncRNAs, best represented by miRNAs, have been known to play an active role in different molecular pathways that are involved in the development and progression of tumors. It has been noticed that changes in miRNA expression levels have effects on cancer phenotypes. In this way, miRNAs can be involved - either as targets or as effectors - in the development of new therapeutic approaches.$^{86}$ On the other hand, dietary phytochemicals have been shown to modulate the expression of miRNAs that are involved in cancer development by acting either as tumor suppressors or as oncogenic miRNAs. Thus, natural compounds such as these have the potential for being used either as direct antitumor agents, or as "helpers" that can assist in reinstating a phenotype that would allow cancer cells to become receptive to chemotherapeutic drugs. ${ }^{87-93}$

Natural compounds have been shown to influence the expression of several miRNAs, which, in turn, modulate important cellular processes, such as reducing inflammation, cell growth, invasion, and metastasis, and promoting epithelial to mesenchymal transition, while stimulating cell differentiation and cell cycle arrest (Figure 2). For example, in the case of EGCG, the natural compound has been shown to upregulate the expression levels of let-7, miR-15, and miR-16, and to inhibit miR-20a. ${ }^{8694}$ An increase in miR-16 expression causes a decrease in the expression of $\mathrm{Bcl} 2$ protein, and consequently apoptosis is enhanced. A similar mechanism occurs when genistein downregulates the expression of miR-20a; this, in fact, leads to an increased expression of proapoptotic gene BclxL. ${ }^{95}$ Furthermore, in vivo studies conducted by Siddiqui et al confirmed findings of a similar kind with an animal model study conducted on mice with prostate cancer, in which reverse transcription PCR (RT-PCR) showed that mice treated with EGCG presented lower levels of the oncomir miR-21 and upregulated levels of the tumor suppressor miR-330. ${ }^{96}$ Once again, these arguments support our claim that green tea polyphenols have anticancer effects, and that their use should be considered in cancer types such as breast and prostate.

Curcumin, the polyphenolic compound from turmeric, displays similar effects on miRNAs: it inhibits oncogenic ones such as miR-21 and miR-186*, while it upregulates tumor suppressors such as miR-15, miR-16, miR-22, miR-27a, and miR-34. ${ }^{94}$ For example, by upregulating miR-22 in pancreatic cancer, curcumin exerts an inhibitory effect on ER $\alpha$ and transcription factor $\mathrm{Sp} 1 .^{97}$ Similarly, the downstream effect is also the promotion of apoptosis, differentiation, and cell cycle arrest, while inhibiting cell growth, invasion, metastasis, and EMT phenotype. ${ }^{83,86}$ Studies have shown that similar effects were also displayed by the synthetic analog of curcumin, which stimulated the expression of tumor suppressor PTEN through the downregulation of miR-21 and miR-200. ${ }^{98}$

The effects that genistein has on hormone-related cancers are similar. In prostate cancer, it upregulates the expression levels of miR-221 and miR-222, leading to the overexpression of tumor suppressor ARH1, which is usually downregulated in this malignancy. ${ }^{99}$ Furthermore, in ovarian cell lines treated with genistein, 53 miRNAs were differentially expressed compared to the untreated samples. Moreover, genistein induced the expression of ERs alpha and beta, while reducing migratory and invasion capabilities of cells. ${ }^{100}$

The results obtained from recent studies support the need to continue shedding light on the way that dietary natural compounds influence tumorigenesis by influencing the levels of miRNAs. Moreover, there is a need to further study other types of ncRNAs that are affected by phytochemical intake. In this regard, Liu et al showed in a microarray study, conducted on hepatocyte cell lines, that EGCG has a modulatory effect on the expression of long ncRNAs potentially involved in cholesterol metabolism. ${ }^{101}$ In a similar way, more studies like this should be performed to see the effect of phytochemicals on long ncRNAs that are involved in tumorigenesis.

In summary, many studies presented in the literature have shown that phytochemicals either act directly on miRNAs and post-transcriptionally modulate gene expression affecting tumor development and progression, or, alternatively, cause a synergistic effect when administered together with conventional drugs. A slight change in the expression of one miRNA can generate a signaling cascade that has the potential to involve many molecular networks and trigger various responses in the tumor cell, specifically in the cancer types that are hormone related. Further studies on this could lead to a more significant understanding of the beneficial effects 


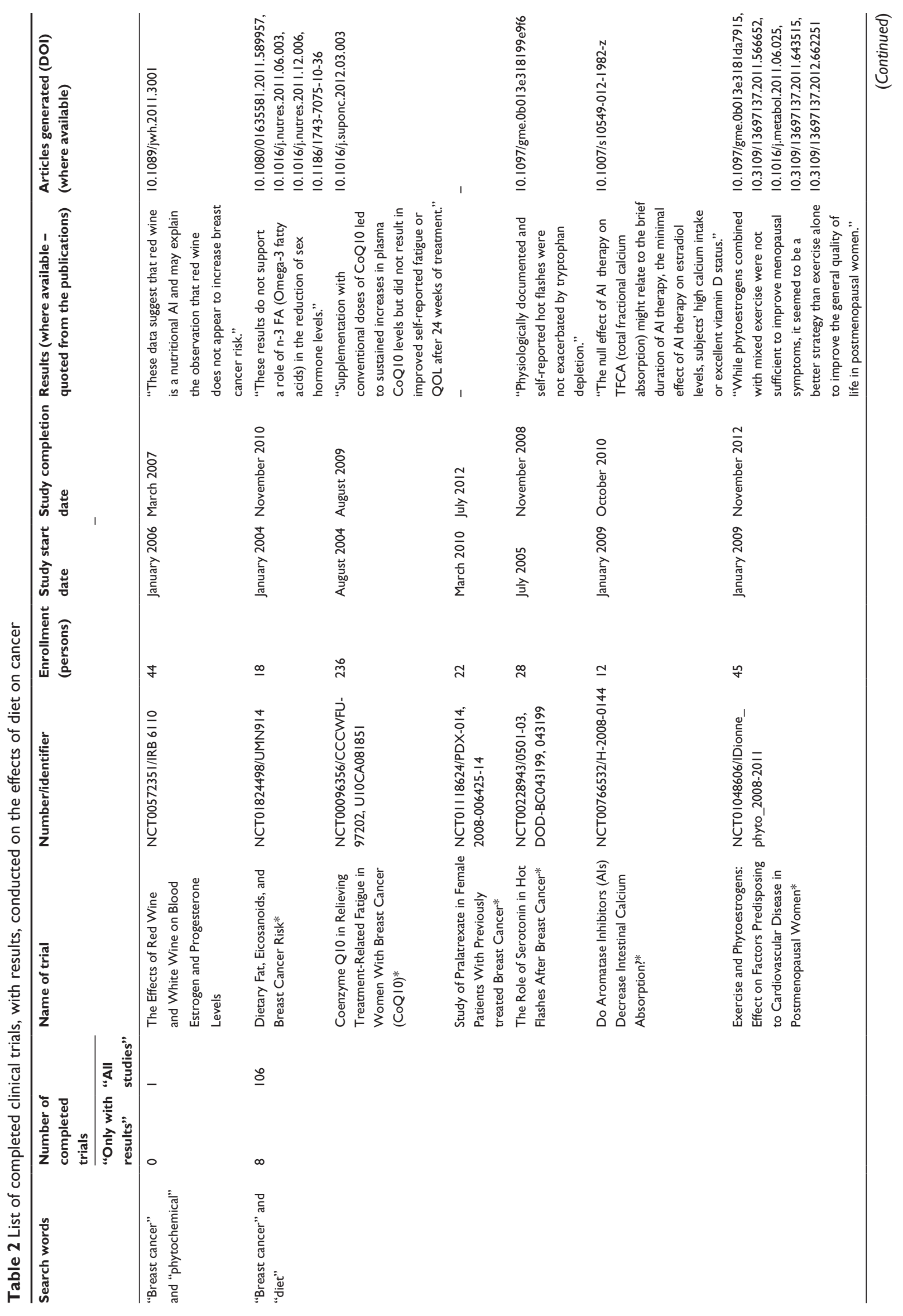




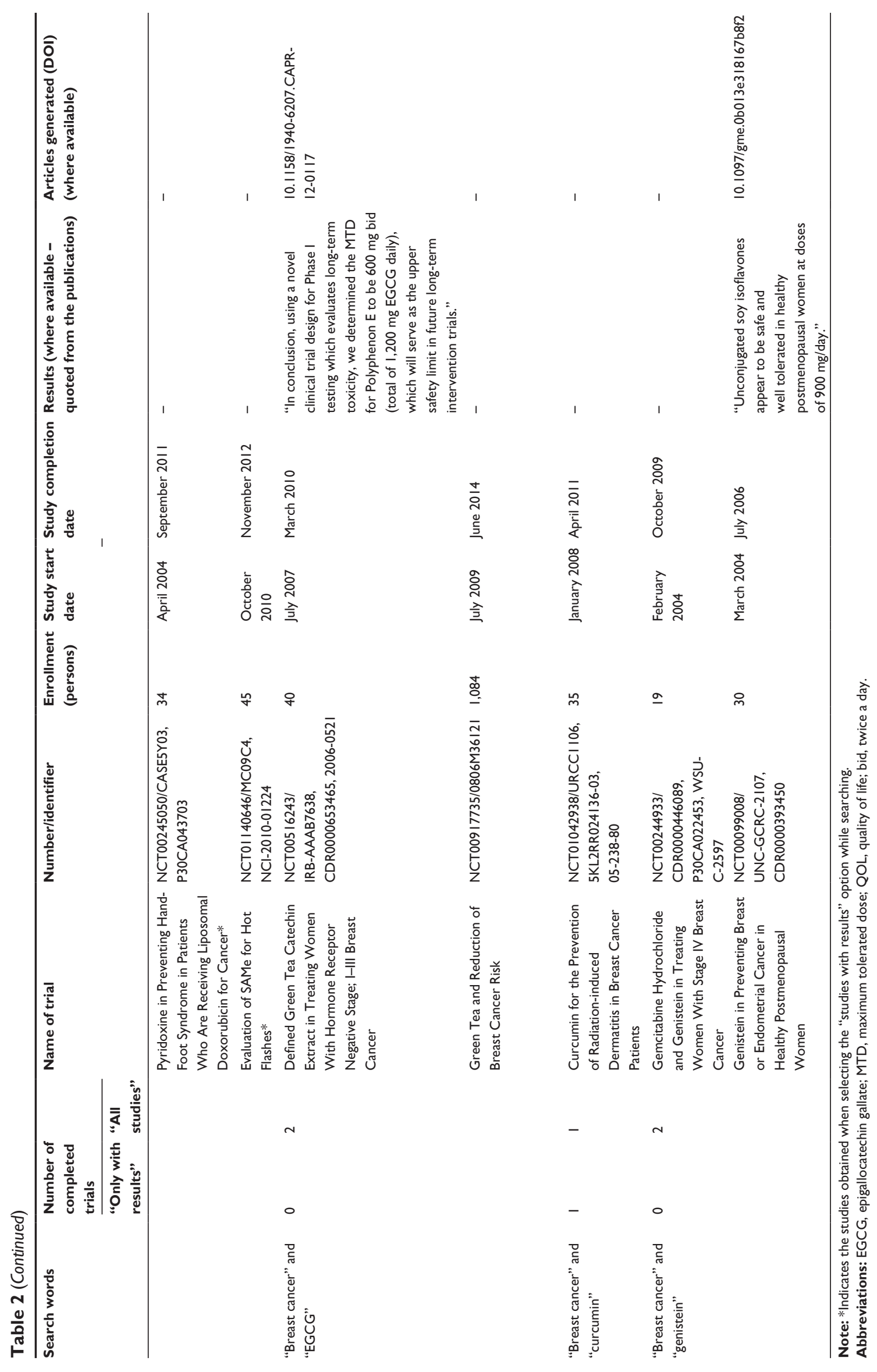


of natural compounds in cancer therapy, and this could lead the way to more effective treatment approaches.

\section{Clinical trials}

At least for the time being, a vast majority of studies have been conducted in an in vitro setting, and the results generated are not yet reaching therapeutic applications, but can be used for a chemopreventive approach. Nonetheless, the increasing number of studies that report success in modulating or influencing the course of hormone-dependent cancers by using natural bioactive compounds offers valuable data that can be useful in the sense of applying the use of dietary supplements such as polyphenols, for example, luteolin, apigenin, EGCG, quercetin, genistein, etc. The ever increasing interest in these phytochemicals and their potential action as nutraceuticals is proven by the large number of studies conducted by different teams worldwide. On the other hand, when it comes to clinical trials, the situation is different. Looking on the www.clinicaltrials.gov website, which, according to its own description, is a resource that offers information on publicly and privately financed clinical trials, the number of studies on humans is not that large. Although the list of trials that was obtained when searching for "diet" and "cancer" consisted of a total of 1,714 interventional studies, the numbers become drastically lower after filters are applied. The results obtained when searching for specific keywords, such as "only completed trials", "only trials that have results", and "exclude unknown status", are presented in Table 2. ${ }^{102-116}$

Nonetheless, there are a lot of researchers interested in continuing studies because of the positive effects that these phytochemicals have on various pathologies. Although at the moment most of the studies are focused on in vitro work, the majority of them need to further validate their results in human subjects. This is bound to change in the future, since the scientific and medical communities are continuously searching for ways to improve human life, also by using natural compounds together with the standard treatments of care.

\section{Conclusion}

Food components have been shown to influence the microenvironment that dictates the cellular response of an organism with regard to immunity, metabolism, responses to stress stimuli, etc. ${ }^{117}$ These scientific approaches promise to evolve to the point where dietary phytochemicals will be used, in a multimodal approach, as multifunctional agents that are capable of stopping or reversing transformation of premalignant cells, before they reach their full tumor phenotype, as well as for the preservation of healthy cells. ${ }^{118}$

As a result of their structure and function, biologically active natural compounds have long been known for their antioxidant, anti-inflammatory, proapoptotic, and antiangiogenic effects, which have been proved by numerous studies conducted mostly on in vitro models. Recent studies, facilitated by modern research tools and concepts, have shown that phytochemicals have the potential of modulating various molecular processes, including signaling pathways involved in the development and progression of tumors. Although we are only beginning to understand the precise way in which these compounds exert their action, there is a clear motivation driving their application together with traditional, chemotherapy, or antihormonal therapy, especially in the case of hormone-dependent cancers. Finally, these types of studies aim to create a greater conscience in human beings in the sense that they can improve their dietary choices, and in this way prevent the development of malignancies such as cancer.

\section{Acknowledgments}

Roxana Cojocneanu Petric is a fellow of POSDRU grant (grant no 159/1.5/S/138776) with title "Model colaborativ institutional pentru translatarea cercetarii stiintifice biomedicale in practica clinica-TRANSCENT". This work was partially funded by PN-II-PT-PCCA-2013 project "Modulation of pro/anticarcinogenic effect of toxic chemical agents in breast cancer multitargeted therapy - CANCERTER".

\section{Disclosure}

The authors report no conflicts of interest in this work.

\section{References}

1. Nilius B, Appendino G. Tasty and healthy TR(i)Ps. The human quest for culinary pungency. EMBO reports. 2011;12(11):1094-1101.

2. Ferlay J SI, Ervik M, Dikshit R, et al. Cancer incidence and mortality worldwide: IARC Cancer Base No 11 [Internet]. GLOBOCAN 2012 v1.0. Lyon, France: International Agency for Research on Cancer; 2013. Available from: http://globocan.iarc.fr. Accessed January 01, 2015.

3. Ducasse M, Brown MA. Epigenetic aberrations and cancer. Mol Cancer. 2006;5:60.

4. Chen HY, Yang YM, Stevens BM, Noble M. Inhibition of redox/Fyn/ c-Cbl pathway function by $\mathrm{Cdc} 42$ controls tumour initiation capacity and tamoxifen sensitivity in basal-like breast cancer cells. EMBO Mol Med. 2013;5(5):723-736.

5. Bunea A, Rugina D, Sconta Z, et al. Anthocyanin determination in blueberry extracts from various cultivars and their antiproliferative and apoptotic properties in B16-F10 metastatic murine melanoma cells. Phytochemistry. 2013;95:436-444.

6. Moiseeva EP, Manson MM. Dietary chemopreventive phytochemicals: too little or too much? Cancer Prev Res. 2009;2(7):611-616.

7. Yang CS, Wang X, Lu G, Picinich SC. Cancer prevention by tea: animal studies, molecular mechanisms and human relevance. Nat Rev Cancer. 2009;9(6):429-439. 
8. Khan N, Mukhtar H. Cancer and metastasis: prevention and treatment by green tea. Cancer Metastasis Rev. 2010;29(3):435-445.

9. Li GX, Chen YK, Hou Z, et al. Pro-oxidative activities and doseresponse relationship of (-)-epigallocatechin-3-gallate in the inhibition of lung cancer cell growth: a comparative study in vivo and in vitro. Carcinogenesis. 2010;31(5):902-910.

10. Shimizu M, Deguchi A, Lim JT, Moriwaki H, Kopelovich L, Weinstein IB. (-)-Epigallocatechin gallate and polyphenon E inhibit growth and activation of the epidermal growth factor receptor and human epidermal growth factor receptor-2 signaling pathways in human colon cancer cells. Clin Cancer Res. 2005;11(7):2735-2746.

11. McLarty J, Bigelow RL, Smith M, Elmajian D, Ankem M, Cardelli JA. Tea polyphenols decrease serum levels of prostate-specific antigen, hepatocyte growth factor, and vascular endothelial growth factor in prostate cancer patients and inhibit production of hepatocyte growth factor and vascular endothelial growth factor in vitro. Cancer Prev Res. 2009;2(7):673-682.

12. Braicu C, Pilecki V, Balacescu O, Irimie A, Neagoe IB. The relationships between biological activities and structure of flavan-3-ols. Int J Mol Sci. 2011;12(12):9342-9353.

13. Chedea VS, Braicu C, Chirila F, et al. Antioxidant/prooxidant and antibacterial/probacterial effects of a grape seed extract in complex with lipoxygenase. Biomed Res Int. 2014;2014:313684.

14. Menendez JA, Quirantes-Pine R, Rodriguez-Gallego E, et al. Oncobiguanides: Paracelsus' law and nonconventional routes for administering diabetobiguanides for cancer treatment. Oncotarget. 2014;5(9): 2344-2348.

15. Shibamoto T, Bjeldanes LF. Introduction to Food Toxicology. Amsterdam, the Netherlands: Elsevier Science; 2009

16. Billam M, Witt AE, Davidson NE. The silent estrogen receptor - can we make it speak? Cancer Biol Ther. 2009;8(6):485-496.

17. Yager JD, Chen JQ. Mitochondrial estrogen receptors - new insights into specific functions. Trends Endocrinol Metab. 2007;18(3):89-91.

18. Massarweh S, Osborne CK, Creighton CJ, et al. Tamoxifen resistance in breast tumors is driven by growth factor receptor signaling with repression of classic estrogen receptor genomic function. Cancer Res. 2008;68(3): $826-833$.

19. Murphy LC, Seekallu SV, Watson PH. Clinical significance of estrogen receptor phosphorylation. Endocr Relat Cancer. 2011;18(1):R1-R14.

20. Gu Y, Chen T, Lopez E, et al. The therapeutic target of estrogen receptoralpha36 in estrogen-dependent tumors. J Transl Med. 2014;12:16.

21. Li Y, Yuan YY, Meeran SM, Tollefsbol TO. Synergistic epigenetic reactivation of estrogen receptor-alpha (ERalpha) by combined green tea polyphenol and histone deacetylase inhibitor in ERalpha-negative breast cancer cells. Mol Cancer. 2010;9:274.

22. Meeran SM, Patel SN, Li Y, Shukla S, Tollefsbol TO. Bioactive dietary supplements reactivate ER expression in ER-negative breast cancer cells by active chromatin modifications. PloS One. 2012;7(5):e37748.

23. Sharma D, Blum J, Yang X, Beaulieu N, Macleod AR, Davidson NE. Release of methyl $\mathrm{CpG}$ binding proteins and histone deacetylase 1 from the estrogen receptor alpha (ER) promoter upon reactivation in ER-negative human breast cancer cells. Mol Endocrinol. 2005;19(7):1740-1751.

24. Bird A. Molecular biology. Methylation talk between histones and DNA. Science. 2001;294(5549):2113-2115.

25. Jenuwein T, Allis CD. Translating the histone code. Science. 2001; 293(5532):1074-1080.

26. Macaluso M, Montanari M, Noto PB, Gregorio V, Bronner C, Giordano A. Epigenetic modulation of estrogen receptor-alpha by $\mathrm{pRb}$ family proteins: $\mathrm{a}$ novel mechanism in breast cancer. Cancer Res. 2007;67(16):7731-7737.

27. Oh AS, Lorant LA, Holloway JN, Miller DL, Kern FG, El-Ashry D. Hyperactivation of MAPK induces loss of ERalpha expression in breast cancer cells. Mol Endocrinol. 2001;15(8):1344-1359.

28. Ramos S. Cancer chemoprevention and chemotherapy: dietary polyphenols and signalling pathways. Mol Nutr Food Res. 2008; 52(5):507-526.

29. Vyas A, Dandawate P, Padhye S, Ahmad A, Sarkar F. Perspectives on new synthetic curcumin analogs and their potential anticancer properties. Curr Pharm Des. 2013;19(11):2047-2069.
30. Aqil F, Munagala R, Jeyabalan J, Vadhanam MV. Bioavailability of phytochemicals and its enhancement by drug delivery systems. Cancer Lett. 2013;334(1):133-141.

31. Sarkar FH, Li Y, Wang Z, Padhye S. Lesson learned from nature for the development of novel anti-cancer agents: implication of isoflavone, curcumin, and their synthetic analogs. Curr Pharm Des. 2010; 16(16): 1801-1812.

32. Tsai YM, Chang-Liao WL, Chien CF, Lin LC, Tsai TH. Effects of polymer molecular weight on relative oral bioavailability of curcumin. Int J Nanomedicine. 2012;7:2957-2966.

33. Yallapu MM, Ebeling MC, Khan S, et al. Novel curcumin-loaded magnetic nanoparticles for pancreatic cancer treatment. Mol Cancer Ther. 2013;12(8):1471-1480.

34. Yallapu MM, Jaggi M, Chauhan SC. Curcumin nanomedicine: a road to cancer therapeutics. Curr Pharm Des. 2013;19(11):1994-2010.

35. Bolton EE, Wang Y, Thiessen PA, Bryant SH. PubChem: integrated platform of small molecules and biological activities. In: Ralph AW, David CS, editors. Annual Reports in Computational Chemistry. Vol 4. Amsterdam, Netherlands: Elsevier; 2008:217-241.

36. Singh BN, Shankar S, Srivastava RK. Green tea catechin, epigallocatechin-3-gallate (EGCG): mechanisms, perspectives and clinical applications. Biochem Pharmacol. 2011;82(12):1807-1821.

37. Thangapazham RL, Singh AK, Sharma A, Warren J, Gaddipati JP, Maheshwari RK. Green tea polyphenols and its constituent epigallocatechin gallate inhibits proliferation of human breast cancer cells in vitro and in vivo. Cancer Lett. 2007;245(1-2):232-241.

38. Sah JF, Balasubramanian S, Eckert RL, Rorke EA. Epigallocatechin3-gallate inhibits epidermal growth factor receptor signaling pathway. Evidence for direct inhibition of ERK1/2 and AKT kinases. J Biol Chem. 2004;279(13):12755-12762.

39. Hastak K, Agarwal MK, Mukhtar H, Agarwal ML. Ablation of either p21 or Bax prevents p53-dependent apoptosis induced by green tea polyphenol epigallocatechin-3-gallate. FASEB J. 2005;19(7):789-791.

40. Nam S, Smith DM, Dou QP. Ester bond-containing tea polyphenols potently inhibit proteasome activity in vitro and in vivo. $J$ Biol Chem. 2001;276(16):13322-13330.

41. Babich H, Krupka ME, Nissim HA, Zuckerbraun HL. Differential in vitro cytotoxicity of (-)-epicatechin gallate (ECG) to cancer and normal cells from the human oral cavity. Toxicol In Vitro. 2005;19(2): 231-242.

42. Yang GY, Liao J, Kim K, Yurkow EJ, Yang CS. Inhibition of growth and induction of apoptosis in human cancer cell lines by tea polyphenols. Carcinogenesis. 1998;19(4):611-616.

43. Kuhn D, Lam WH, Kazi A, et al. Synthetic peracetate tea polyphenols as potent proteasome inhibitors and apoptosis inducers in human cancer cells. Front Biosci. 2005;10:1010-1023.

44. Russo M, Spagnuolo C, Tedesco I, Russo GL. Phytochemicals in cancer prevention and therapy: truth or dare? Toxins. 2010;2(4):517-551.

45. Scandlyn MJ, Stuart EC, Somers-Edgar TJ, Menzies AR, Rosengren RJ. A new role for tamoxifen in oestrogen receptor-negative breast cancer when it is combined with epigallocatechin gallate. Br J Cancer. 2008; 99(7):1056-1063.

46. Yunos NM, Beale P, Yu JQ, Huq F. Synergism from the combination of oxaliplatin with selected phytochemicals in human ovarian cancer cell lines. Anticancer Res. 2011;31(12):4283-4289.

47. Chen C, Yu R, Owuor ED, Kong AN. Activation of antioxidant-response element (ARE), mitogen-activated protein kinases (MAPKs) and caspases by major green tea polyphenol components during cell survival and death. Arch Pharm Res. 2000;23(6):605-612.

48. Nishikawa T, Nakajima T, Moriguchi M, et al. A green tea polyphenol, epigalocatechin-3-gallate, induces apoptosis of human hepatocellular carcinoma, possibly through inhibition of Bcl-2 family proteins. J Hepatol. 2006;44(6):1074-1082.

49. Lee YK, Bone ND, Strege AK, Shanafelt TD, Jelinek DF, Kay NE. VEGF receptor phosphorylation status and apoptosis is modulated by a green tea component, epigallocatechin-3-gallate (EGCG), in B-cell chronic lymphocytic leukemia. Blood. 2004;104(3):788-794. 
50. Berindan-Neagoe I, Braicu C, Irimie A. Combining the chemotherapeutic effects of epigallocatechin 3-gallate with siRNA-mediated p53 knock-down results in synergic pro-apoptotic effects. Int J Nanomedicine. 2012;7:6035-6047.

51. Berindan-Neagoe I, Braicu C, Tudoran O, Balacescu O, Irimie A. Early apoptosis signals induced by a low dose of epigallocatechin 3 -gallate interfere with apoptotic and cell death pathways. $J$ Nanosci Nanotechnol. 2012;12(3):2113-2119.

52. Zhou Y, Eppenberger-Castori S, Eppenberger U, Benz CC. The NFkappaB pathway and endocrine-resistant breast cancer. Endocr Relat Cancer. 2005;12(suppl 1):S37-S46.

53. Perkins ND, Gilmore TD. Good cop, bad cop: the different faces of NF-kappaB. Cell Death Differ. 2006;13(5):759-772.

54. Pianetti S, Guo S, Kavanagh KT, Sonenshein GE. Green tea polyphenol epigallocatechin-3 gallate inhibits Her-2/neu signaling, proliferation, and transformed phenotype of breast cancer cells. Cancer Res. 2002;62(3):652-655

55. Miller TE, Ghoshal K, Ramaswamy B, et al. MicroRNA-221/222 confers tamoxifen resistance in breast cancer by targeting p27Kip1. J Biol Chem. 2008;283(44):29897-29903.

56. Rao X, Di Leva G, Li M, et al. MicroRNA-221/222 confers breast cancer fulvestrant resistance by regulating multiple signaling pathways. Oncogene. 2011;30(9):1082-1097.

57. Grynkiewicz G, Slifirski P. Curcumin and curcuminoids in quest for medicinal status. Acta Bioch Pol. 2012;59(2):201-212.

58. Esatbeyoglu T, Huebbe P, Ernst IM, Chin D, Wagner AE, Rimbach G. Curcumin - from molecule to biological function. Angew Chem Int Ed Engl. 2012;51(22):5308-5332.

59. Jurenka JS. Anti-inflammatory properties of curcumin, a major constituent of Curcuma longa: a review of preclinical and clinical research. Altern Med Rev. 2009;14(2):141-153.

60. Dhillon N, Aggarwal BB, Newman RA, et al. Phase II trial of curcumin in patients with advanced pancreatic cancer. Clin Cancer Res. 2008;14(14):4491-4499.

61. Kunnumakkara AB, Diagaradjane P, Guha S, et al. Curcumin sensitizes human colorectal cancer xenografts in nude mice to gamma-radiation by targeting nuclear factor-kappaB-regulated gene products. Clin Cancer Res. 2008;14(7):2128-2136.

62. Weir NM, Selvendiran K, Kutala VK, et al. Curcumin induces G2/M arrest and apoptosis in cisplatin-resistant human ovarian cancer cells by modulating Akt and p38 MAPK. Cancer Biol Ther. 2007;6(2): $178-184$

63. Woo JH, Kim YH, Choi YJ, et al. Molecular mechanisms of curcumininduced cytotoxicity: induction of apoptosis through generation of reactive oxygen species, down-regulation of Bcl-XL and IAP, the release of cytochrome $\mathrm{c}$ and inhibition of Akt. Carcinogenesis. 2003;24(7):1199-1208.

64. Martin PM, Horwitz KB, Ryan DS, McGuire WL. Phytoestrogen interaction with estrogen receptors in human breast cancer cells. Endocrinology. 1978;103(5):1860-1867.

65. Lavigne JA, Takahashi Y, Chandramouli GV, et al. Concentrationdependent effects of genistein on global gene expression in MCF-7 breast cancer cells: an oligo microarray study. Breast Cancer Res Treat. 2008;110(1):85-98.

66. Mahmoud AM, Yang W, Bosland MC. Soy isoflavones and prostate cancer: a review of molecular mechanisms. J Steroid Biochem Mol Biol. 2014;140:116-132.

67. Banerjee S, Li Y, Wang Z, Sarkar FH. Multi-targeted therapy of cancer by genistein. Cancer Lett. 2008;269(2):226-242.

68. Li Y, Ahmed F, Ali S, Philip PA, Kucuk O, Sarkar FH. Inactivation of nuclear factor kappaB by soy isoflavone genistein contributes to increased apoptosis induced by chemotherapeutic agents in human cancer cells. Cancer Res. 2005;65(15):6934-6942.

69. Gong L, Li Y, Nedeljkovic-Kurepa A, Sarkar FH. Inactivation of NFkappaB by genistein is mediated via Akt signaling pathway in breast cancer cells. Oncogene. 2003;22(30):4702-4709.

70. Hilakivi-Clarke L, Andrade JE, Helferich W. Is soy consumption good or bad for the breast? $J$ Nutr. 2010;140(12):2326S-2334S.
71. Davis JN, Kucuk O, Djuric Z, Sarkar FH. Soy isoflavone supplementation in healthy men prevents NF-kappa B activation by TNF-alpha in blood lymphocytes. Free Radic Biol Med. 2001;30(11):1293-1302.

72. Anastasius N, Boston S, Lacey M, Storing N, Whitehead SA. Evidence that low-dose, long-term genistein treatment inhibits oestradiolstimulated growth in MCF-7 cells by down-regulation of the PI3kinase/Akt signalling pathway. J Steroid Biochem Mol Biol. 2009; 116(1-2):50-55.

73. Sahin K, Tuzcu M, Sahin N, et al. Inhibitory effects of combination of lycopene and genistein on 7,12-dimethyl benz(a)anthracene-induced breast cancer in rats. Nutr Cancer. 2011;63(8):1279-1286.

74. Kikuno N, Shiina H, Urakami S, et al. Genistein mediated histone acetylation and demethylation activates tumor suppressor genes in prostate cancer cells. Int J Cancer. 2008;123(3):552-560.

75. Basak S, Pookot D, Noonan EJ, Dahiya R. Genistein down-regulates androgen receptor by modulating HDAC6-Hsp90 chaperone function. Mol Cancer Ther. 2008;7(10):3195-3202.

76. Su Y, Simmen FA, Xiao R, Simmen RC. Expression profiling of rat mammary epithelial cells reveals candidate signaling pathways in dietary protection from mammary tumors. Physiol Genomics. 2007;30(1): $8-16$.

77. Wang Z, Zhang Y, Li Y, Banerjee S, Liao J, Sarkar FH. Down-regulation of Notch-1 contributes to cell growth inhibition and apoptosis in pancreatic cancer cells. Mol Cancer Ther. 2006;5(3):483-493.

78. Ziegler RG, Hoover RN, Pike MC, et al. Migration patterns and breast cancer risk in Asian-American women. J Natl Cancer Inst. 1993;85(22): 1819-1827.

79. Shu XO, Jin F, Dai Q, et al. Soyfood intake during adolescence and subsequent risk of breast cancer among Chinese women. Cancer Epidemiol Biomarkers Prev. 2001;10(5):483-488.

80. Wu AH, Wan P, Hankin J, Tseng CC, Yu MC, Pike MC. Adolescent and adult soy intake and risk of breast cancer in Asian-Americans. Carcinogenesis. 2002;23(9):1491-1496.

81. Korde LA, Wu AH, Fears T, et al. Childhood soy intake and breast cancer risk in Asian American women. Cancer Epidemiol Biomarkers Prev. 2009;18(4):1050-1059.

82. Lee SA, Shu XO, Li H, et al. Adolescent and adult soy food intake and breast cancer risk: results from the Shanghai Women's Health Study. Am J Clin Nutr. 2009;89(6):1920-1926.

83. Huang J, Plass C, Gerhauser C. Cancer chemoprevention by targeting the epigenome. Curr Drug Targets. 2011;12(13):1925-1956.

84. Setchell KD, Cole SJ. Variations in isoflavone levels in soy foods and soy protein isolates and issues related to isoflavone databases and food labeling. J Agric Food Chem. 2003;51(14):4146-4155.

85. Fang N, Yu S, Badger TM. Comprehensive phytochemical profile of soy protein isolate. J Agric Food Chem. 2004;52(12):4012-4020.

86. Neelakandan K, Babu P, Nair S. Emerging roles for modulation of microRNA signatures in cancer chemoprevention. Curr Cancer Drug Targets. 2012;12(6):716-740

87. Garzia L, Andolfo I, Cusanelli E, et al. MicroRNA-199b-5p impairs cancer stem cells through negative regulation of HES1 in medulloblastoma. PloS One. 2009;4(3):e4998.

88. Blower PE, Verducci JS, Lin S, et al. MicroRNA expression profiles for the NCI-60 cancer cell panel. Mol Cancer Ther. 2007;6(5): 1483-1491.

89. Yang $\mathrm{H}$, Kong $\mathrm{W}, \mathrm{He} \mathrm{L}$, et al. MicroRNA expression profiling in human ovarian cancer: miR-214 induces cell survival and cisplatin resistance by targeting PTEN. Cancer Res. 2008;68(2):425-433.

90. Yang N, Kaur S, Volinia S, et al. MicroRNA microarray identifies Let-7i as a novel biomarker and therapeutic target in human epithelial ovarian cancer. Cancer Res. 2008;68(24):10307-10314.

91. Sorrentino A, Liu CG, Addario A, Peschle C, Scambia G, Ferlini C. Role of microRNAs in drug-resistant ovarian cancer cells. Gynecol Oncol. 2008;111(3):478-486.

92. Zhu H, Wu H, Liu X, et al. Role of MicroRNA miR-27a and miR-451 in the regulation of MDR1/P-glycoprotein expression in human cancer cells. Biochem Pharmacol. 2008;76(5):582-588. 
93. Wendler A, Keller D, Albrecht C, Peluso JJ, Wehling M. Involvement of let-7/miR-98 microRNAs in the regulation of progesterone receptor membrane component 1 expression in ovarian cancer cells. Oncol Rep. 2011;25(1):273-279.

94. Li Y, Kong D, Wang Z, Sarkar FH. Regulation of microRNAs by natural agents: an emerging field in chemoprevention and chemotherapy research. Pharm Res. 2010;27(6):1027-1041.

95. Tsang WP, Kwok TT. Epigallocatechin gallate up-regulation of miR-16 and induction of apoptosis in human cancer cells. J Nutr Biochem. 2010;21(2):140-146.

96. Siddiqui IA, Asim M, Hafeez BB, Adhami VM, Tarapore RS, Mukhtar H. Green tea polyphenol EGCG blunts androgen receptor function in prostate cancer. FASEB J. 2011;25(4):1198-1207.

97. Sun M, Estrov Z, Ji Y, Coombes KR, Harris DH, Kurzrock R. Curcumin (diferuloylmethane) alters the expression profiles of microRNAs in human pancreatic cancer cells. Mol Cancer Ther. 2008;7(3): 464-473.

98. Bao B, Ali S, Kong D, et al. Anti-tumor activity of a novel compoundCDF is mediated by regulating miR-21, miR-200, and PTEN in pancreatic cancer. PloS One. 2011;6(3):e17850.

99. Chen Y, Zaman MS, Deng G, et al. MicroRNAs 221/222 and genisteinmediated regulation of ARHI tumor suppressor gene in prostate cancer. Cancer Prev Res. 2011;4(1):76-86.

100. Parker LP, Taylor DD, Kesterson J, Metzinger DS, Gercel-Taylor C. Modulation of microRNA associated with ovarian cancer cells by genistein. Eur J Gynaecol Oncol. 2009;30(6):616-621.

101. Liu G, Zheng X, Xu Y, Lu J, Chen J, Huang X. Long Non-coding RNAs expression profile in HepG2 cells reveals the potential role of long noncoding RNAs in the cholesterol metabolism. Chin Med J. 2015;128(1): 91-97.

102. Shufelt C, Merz CN, Yang Y, et al. Red versus white wine as a nutritional aromatase inhibitor in premenopausal women: a pilot study. $J$ Womens Health. 2012;21(3):281-284.

103. Young LR, Kurzer MS, Thomas W, Redmon JB, Raatz SK. Effect of dietary fat and omega-3 fatty acids on urinary eicosanoids and sex hormone concentrations in postmenopausal women: a randomized controlled feeding trial. Nutr Cancer. 2011;63(6):930-939.

104. McColley SP, Georgopoulos A, Young LR, Kurzer MS, Redmon JB, Raatz SK. A high-fat diet and the threonine-encoding allele (Thr54) polymorphism of fatty acid-binding protein 2 reduce plasma triglyceride-rich lipoproteins. Nutr Res. 2011;31(7):503-508.

105. Raatz SK, Young LR, Picklo MJ Sr, Sauter ER, Qin W, Kurzer MS. Total dietary fat and fatty acid content modifies plasma phospholipid fatty acids, desaturase activity indices, and urinary prostaglandin $\mathrm{E}$ in women. Nutr Res. 2012;32(1):1-7.
106. Young LR, Raatz SK, Thomas W, Redmon JB, Kurzer MS. Total dietary fat and omega-3 fatty acids have modest effects on urinary sex hormones in postmenopausal women. Nutr Metabol. 2013;10(1):36.

107. Lesser GJ, Case D, Stark N, et al. A randomized, double-blind, placebo-controlled study of oral coenzyme Q10 to relieve self-reported treatment-related fatigue in newly diagnosed patients with breast cancer. J Support Oncol. 2013;11(1):31-42.

108. Carpenter JS, Yu M, Wu J, et al. Evaluating the role of serotonin in hot flashes after breast cancer using acute tryptophan depletion. Menopause. 2009;16(4):644-652.

109. Tevaarwerk A, Burkard ME, Wisinski KB, et al. Aromatase inhibitors and calcium absorption in early stage breast cancer. Breast Cancer Res Treat. 2012;134(1):245-251.

110. Riesco E, Aubertin-Leheudre M, Maltais ML, Audet M, Dionne IJ. Synergic effect of phytoestrogens and exercise training on cardiovascular risk profile in exercise-responder postmenopausal women: a pilot study. Menopause. 2010;17(5):1035-1039.

111. Riesco E, Choquette S, Audet M, Tessier D, Dionne IJ. Effect of exercise combined with phytoestrogens on quality of life in postmenopausal women. Climacteric: the Journal of the International Menopause Society. 2011;14(5):573-580.

112. Riesco E, Choquette S, Audet M, Lebon J, Tessier D, Dionne IJ. Effect of exercise training combined with phytoestrogens on adipokines and C-reactive protein in postmenopausal women: a randomized trial. Metabolism. 2012;61(2):273-280.

113. Choquette S, Dion T, Brochu M, Dionne IJ. Soy isoflavones and exercise to improve physical capacity in postmenopausal women. Climacteric. 2013;16(1):70-77.

114. Barsalani R, Riesco E, Lavoie JM, Dionne IJ. Effect of exercise training and isoflavones on hepatic steatosis in overweight postmenopausal women. Climacteric. 2013;16(1):88-95.

115. Crew KD, Brown P, Greenlee H, et al. Phase IB randomized, doubleblinded, placebo-controlled, dose escalation study of polyphenon $\mathrm{E}$ in women with hormone receptor-negative breast cancer. Cancer Prev Res. 2012;5(9):1144-1154.

116. Pop EA, Fischer LM, Coan AD, Gitzinger M, Nakamura J, Zeisel SH. Effects of a high daily dose of soy isoflavones on DNA damage, apoptosis, and estrogenic outcomes in healthy postmenopausal women: a phase I clinical trial. Menopause. 2008;15(4 Pt 1):684-692.

117. Vanden Berghe W. Epigenetic impact of dietary polyphenols in cancer chemoprevention: lifelong remodeling of our epigenomes. Pharmacol Res. 2012;65(6):565-576.

118. Parasramka MA, Ho E, Williams DE, Dashwood RH. MicroRNAs, diet, and cancer: new mechanistic insights on the epigenetic actions of phytochemicals. Mol Carcinog. 2012;51(3):213-230.
OncoTargets and Therapy

\section{Publish your work in this journal}

OncoTargets and Therapy is an international, peer-reviewed, open access journal focusing on the pathological basis of all cancers, potential targets for therapy and treatment protocols employed to improve the management of cancer patients. The journal also focuses on the impact of management programs and new therapeutic agents and protocols on
Dovepress

patient perspectives such as quality of life, adherence and satisfaction. The manuscript management system is completely online and includes a very quick and fair peer-review system, which is all easy to use. Visit http://www.dovepress.com/testimonials.php to read real quotes from published authors. 